\title{
Kazakhstan's experience in reducing infant and child mortality
}

\author{
Tamara Chuvakova', Magripa Emberg \\ ${ }^{1}$ National research center for maternal and child health \\ of the corporate fund "UMC», Astana, Kazakhstan
}

This work is licensed under a Creative Commons Attribution 4.0 International License

J CLIN MED KAZ 2017; 3(45 SUPPL 3):150-153 Corresponding author: Чувакова Т.К., отдел неонатологии, Национальный научный центр материнства и детства корпоративного фонда «UMC» Адрес: 010000 Казахстан, г. Астана, пр. Туран 32. Телефон +77019996880.

Электронный адрес:ch.tamara@mail.ru.

\section{Введение}

Уровни материнской, младенческой и детской смертности являются ключевыми показателями качества работы системы здравоохранения и используются для принятия управленческих решений по их совершенствованию. Проблемы их снижения решаются в Республике Казахстан через национальные процессы планирования и государственную политику. В частности, через Национальную стратегию развития РК (Стратегия 2030), а также путем выполнения международных обязательств в рамках Декларации Тысячелетия по снижению детской смертности и улучшению материнского

\section{ABSTRACT}

Healthcare reforms contributed to the implementation of MDG 4 in Kazakhstan, which of mortality rate (2014): "Kazakhstan, since 1990, made significant progress in reducing infant and child mortality by $64 \%$ and $65 \%$, respectively. The country has fulfilled the MDG 4 on reducing child mortality from 0 to 5 years by 2014 ". mortality.

Key words: the Millennium Development Goals, child and infant and neonatal

ТҰЖЫРЫМДАМА

БАЛАЛАРДЫН ӨЛІМ-ЖІТІМІН ТӨМЕНДЕТУ БОЙЫНША 4-ШІ

МЫНЖЫЛДЫК ДАМУ МАКСАТЫН ЖҮЗЕГЕ АСЫРУДАҒЫ

Шуакова Т.К. ${ }^{1}$, Ембергенова М.Х. ${ }^{1}$, Карин Б.Т. ${ }^{1}$

Денсаулык саласында жүргізген реформалар Қазақстан Республикасында мыңжылдық даму мақсаттарын орындауға мүмкіндік берді, бұл Біріккен Ұлттар Ұйымының салааралық топтың келіскен шешімімен өлім деңгейін бағалауында расталынды (2014 жыл): Қазақстан 1990 жылдан бала және сәби өлімін төмендету бағытында үлкен жетістіктерге жетті, 65\% және 64\%-ке төмендетті. Қазақстан мыңжылдық даму дейін түсірді.

Маңызды сөздер: Мыңжылдық алдындағы даму мақсаттырының балалар

PEЗЮME

ОПЫТ КАЗАХСТАНА В ВЫПОЛНЕНИИ 4-ОЙ ЦЕЛИ РАЗВИТИЯ ТЫСЯЧЕЛЕТИЯ ПО СНИЖЕНИЮ ДЕТСКОЙ СМЕРТНОСТИ

Чувакова Т.К. ${ }^{1}$, Ембергенова М.Х. ${ }^{1}$, Карин Б.Т. ${ }^{1}$

Проведенные реформы здравоохранения способствовали выполнению ЦРТ 4 в Казахстане, что подтверждается Согласованным заключением Межведомственной Группы Организации Объединенных Наций по оценке уровня смертности (2014 г): «Казахстан, начиная с 1990 г, добился значительного прогресса в снижении младенческой и детской смертности на 64\% и 65\% соответственно. Страна выполнила ЦРТ 4 по снижению смертности детей от 0 до 5 лет к 2014 году».

Ключевые слова: Цели развития на пороге тысячелетия (ЦРТ), детская, младенческая и неонатальная смертность.

здоровья до 2015г.

Придавая особое значение своевременному достижению Целей развития тысячелетия, министерствм здравоохранения РК при технической поддержке регионального офиса ЮНИСЕФ, был проведен анализ причин младенческой и детской смертности в Казахстане [1]. Результаты анализа были положены в основу 1-го отчета Правительства РК и Представительства ООН в Казахстане о возможности выполнения Целей тысячелетия [2], который был доложен на заседании Парламента РК в ноябре 2005г: «Снижение детской смертности в Казахстане: ситуация, проблемы, ключевые интервенции» [3]. 
Анализ показал, что уровень детской смертности можно значительно снизить при условии:

1) улучшения учета и анализа статистических данных;

2) совершенствования перинатального ухода;

3) адекватного клинического ведения болезней детского возраста и патронажного наблюдения за детьми на уровне ПМСП.

С целью получения полной и достоверной информации о всех родившихся и умерших младенцах, с января 2008 года Казахстан перешел на регистрацию случаев живорождения и мертворождения в соответствии с меджународными критериями, рекомендованными Всемирной организацией здравоохранения [4]. В этой связи в национальную перинатальную статистику внесены плоды и новорожденные, имеющие массу тела при рождении 500 грамм и более, родившиеся с гестационным возрастом 22 недели и более, имеющие длину тела 25 сантиметров и более. Для разработки и осуществления адекватных вмешательств и рационального распределения ресурсов на всех уровнях системы, ответственных за выживание детей, статистические данные стали представляться в разбивке по весовым категориям и периоду смерти с использованием методологии BABIES [5].

Методология "ВАBIES" является одним из инструментов, предусматривающих обязательный учет всех перинатальных рождений и потерь, так как расчет специфических показателей плодово-младенческих потерь проводится с учетом первоначальной массы тела родившихся и умерших на первом году жизни. Этот инструмент позволяет проводить мониторинг и оценку мероприятий по улучшению охраны здоровья детей, своевременно выявлять проблемы, возникающие в практике родовспоможения и проводить адекватную коррекцию путем выбора соответствующего пакета вмешательств.

Как и ожидалось, в связи с расширением критериев живорождения и мертворождения в 2008 году повысились показатели плодово-младенческих потерь (табл. 1). Так, по сравнению с показателями без учета плодов и новорожденных с массой тела 500-999 г, мертворождаемость повысилась на 40,8\%, перинатальная смертность на 37,6\%, ранняя неонатальная смертность на $36 \%$ и младенческая смертность на $21,4 \%$.

Основную долю плодово-младенческих потерь

Таблица 1 Показатели плодово-младенческих потерь в Казахстане за 2008г (на 1000 родившихся живыми).

\begin{tabular}{|l|l|l|l|l|l|l|l|}
\hline & Мертворождаемость & $\begin{array}{l}\text { Ранняя } \\
\text { неонатальная } \\
\text { смертно-сть }\end{array}$ & $\begin{array}{l}\text { Перинатальная } \\
\text { смертность }\end{array}$ & $\begin{array}{l}\text { Поздняя } \\
\text { неонатальная } \\
\text { смертность }\end{array}$ & $\begin{array}{l}\text { Неона-тальная } \\
\text { смерт-ность }\end{array}$ & $\begin{array}{l}\text { Постнео- } \\
\text { натальная } \\
\text { смертно-сть }\end{array}$ & $\begin{array}{l}\text { Младенческая } \\
\text { смертно-сть }\end{array}$ \\
\hline $\begin{array}{l}\text { С учетом новорожд. с } \\
\text { массой тела 500- 999 г }\end{array}$ & 10,7 & 12,1 & 22,6 & 2,8 & 14,9 & 20,4 \\
\hline $\begin{array}{l}\text { Без учета новорожд. с } \\
\text { массой тела 500-999г }\end{array}$ & 7,6 & 8,9 & 16,5 & 2,5 & 11,4 & 5,4 \\
\hline Прирост показателя в \% & 40,8 & 36,0 & 37,6 & 12,0 & 30,7 & 1,8 \\
\hline
\end{tabular}

(рис.1) составляли новорожденные, умершие в раннем неонатальном периоде $(38,9 \%)$, мертворожденные $(34,4 \%)$, а также младенцы, умершие в постнеонатальном периоде $(17,7 \%)$. В позднем неонатальном периоде потери детей были наименьшими ( 9,0\%).

При этом умирали практически все новорожденные с чрезвычайно малой массой тела при рождении (до 1000 г), каждый второй с массой тела менее 1500 грамм и каждый седьмой с массой тела при рождении от 1500 до 2499 грамм (табл.2).

Существенные потери были зарегистрированы и среди 2008r.

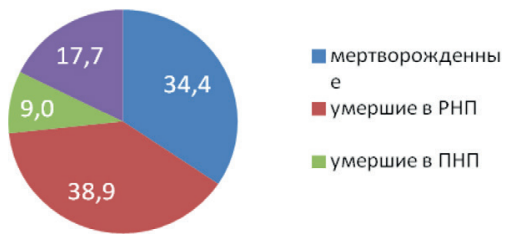

Рисунок 1 - Структура плодово-младенческих потерь в РК в 2008г.

РНП - ранний неонатальный период. ПНП - поздний неонатальный период. ПостНП - постнеонатальный период.

Таблища 1 Специфический показатель мертворождаемости и смертности младенцев в Казахстане в 2008 г. (на 1000 родившихся в соответствующей весовой категории).

\begin{tabular}{|c|c|c|c|c|c|c|}
\hline \multirow{2}{*}{$\begin{array}{l}\text { Масса тела при рождении в } \\
\text { граммах }\end{array}$} & \multicolumn{6}{|c|}{ Время наступления смерти } \\
\hline & Антенатально & Интранатально & 0-6 дней & 7-28 дней & 28 дн-1год & всего \\
\hline $500-999$. & 344,5 & 77,4 & 440,1 & 43,2 & 20,8 & 926 \\
\hline $1500-2499$ & 43,1 & 5,8 & 59,7 & 14,4 & 18,9 & 141,8 \\
\hline 2500 и > & 2,7 & 0,9 & 3,5 & 1,3 & 4,3 & 12,6 \\
\hline Всего & 8,8 & 1,9 & 12 & 2,8 & 5,4 & 30,9 \\
\hline
\end{tabular}

500-999г - масса тела при рождении. 1000-1499 - масса тела при рождении. 1500-2499 - масса тела при рождении. 2500 и более - масса тела при рождении. Рисунок 2 - Факторы, определяющие плодово-младенческие потери в Казахстане, 2008 год

младенцев с нормальной массой тела при рождении (2500 г и более) - 12.6\%, которые погибали преимущественно в раннем неонатальном (3.5\%) и постнеонатальном периодах (4.3\%o). Показатель мертворождаемости в данной весовой категории был также достаточно высоким (3.6\%)

Согласно методологии "BABIES", было показано (рис.2), что в Казахстане в 2008 г наиболее важным фактором, определяющем плодово-младенческие потери, являлось состояние здоровья женщин $(11,5 \%)$ - основной причины преждевременного рождения младенцев с чрезвычайно низкой (от 500 до 999 г) и очень низкой (от 1000 до 1490 г) массой тела. 


\begin{tabular}{|c|c|c|c|}
\hline $500-999 \Gamma$ & \multicolumn{3}{|c|}{ Здоровье женщин до беременности: } \\
\hline $11,5 \% 0$ & & & \\
\hline $1000-1499$ & \multirow{3}{*}{$\begin{array}{c}\text { Уход за } \\
\text { беременной } \\
\text { женщиной: } \\
\text { 6,0\%о }\end{array}$} & \multirow{3}{*}{$\begin{array}{c}\text { Уход за } \\
\text { новорожденным: } \\
7,2 \% 0\end{array}$} & \multirow{3}{*}{$\begin{array}{c}\text { Уход за } \\
\text { младенцем: } \\
6,2 \% \text { o }\end{array}$} \\
\hline $1500-2499$ & & & \\
\hline 2500 и более & & & \\
\hline
\end{tabular}

Рисунок 2- Факторы, определяющие плодово-младенческие потери в Казахстане, 2008 год

500-999Г - масса тела при рождении. 1000-1499 - масса тела при рождении.

1500-2499 - масса тела при рождении. 2500 и более - масса тела при рождении.

На втором месте по значимости определены нарушения организации и ухода за новорожденными в родовспомогательных организациях (7,2\%), на 3-ем - уход за младенцем после выписки из родильного дома $(6,2 \%)$ и, наконец, уход за беременной женщиной, включающий антенатальный уход и оказание помощи роженице в родах (6,0\%о) при общих плодово-младенческих потерях 30,9\%о $\left(11,5 \%{ }_{0}+7,2 \%{ }_{0}+6,2 \%\right.$ o $+6,0 \%$ ).

Таким образом, анализ плодово-младенческих потерь по весовым категориям и периодам смертности, а также факторам, определяющим эти потери, позволил выявить степень значимости каждого из них в структуре смертности и сделать выбор по приоритетности интервенций. Были определены пакеты вмешательств с приоритетным распределением ресурсов в рамках реализации национальных программ, разработанных Министерством здравоохранения РК: «Государственная программа реформирования и развития здравоохранения Республики Казахстан на 2005-2010 гг», утвержденная Указом Президента Республики Казахстан от 13 сентября 2004 г., №1438 и «Программа по снижению материнской и детской смертности в Республике Казахстан на 20082010 годы», утвержденная постановлением Правительства Республики Казахстан от 28 декабря 2007 г, №1325.

С целью совершенствования перинатального ухода в стране стали внедряться программы ВО3 «Безопасная беременность» и «Эффективный перинатальный уход» [6] с проведением регионализации перинатальной помощи во всех 16 регионах страны. Адекватное клиническое ведение болезней детского возраста и патронажное наблюдение за детьми на уровне первичной медико-санитарной помощи было обеспечено внедрением стратегий ВО3 по оказанию стационарной помощи детям и интегрированному введению болезней детского возраста (ИВБДВ) на амбулаторном уровне $[7,8,9]$. Разработаны и внедрены в практику клинические руководстваипротоколыдиагностики илечения заболеваний детей от 0 до 5 лет на основе международных рекомендаций, основанных на доказательной медицине.

Проведенные в Казахстане реформы здравоохранения обеспечили позитивные результаты в плане улучшения качества оказываемых услуг в системе охраны здоровья матери и ребенка.

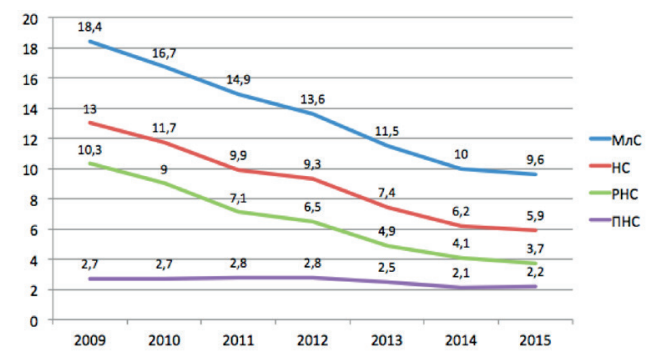

Рисунок 3- Динамика младенческой и неонатальной смертности в РК.

МлС- младенческая смертность; НС - неонатальная смертность; РНС ранняя неонатальная смертность; ПНС - поздняя неонатальная смертность.
С 2009 г наметилось устойчивое снижение показателя младенческой смертности, уровень которой к 2015 г составил 9,6\%о (рис.3). Снижение МС было обусловлено уменьшением потерь в раннем неонатальном периоде в 3 раза: с 12,0\%о в 2008 г до 3,7\% в 2015 г за счет повышения выживаемости маловесных детей, как с экстремально низкой (менее 1000 г) и очень низкой (менее 1500 г) массой тела при рождении (табл.3).

Таблица 1 Выживаемость среди новорожденных с экстремально низкой и очень низкой массой тела до 1 года в РК за 1-е полугодие 20142015 гг.

\begin{tabular}{|l|l|l|}
\hline & 2014 г & 2015 г \\
\hline $500,0-999,0$ & $37 \%$ & $40,8 \%$ \\
\hline $1000,0-1499,0$ & $77 \%$ & $76 \%$ \\
\hline
\end{tabular}

Произошли и структурные изменения плодовомладенческих потерь в Казахстане за период 2009-2015 гг, повлиявшие и на распределение факторов, определяющих пакеты вмешательств (рис. 4).

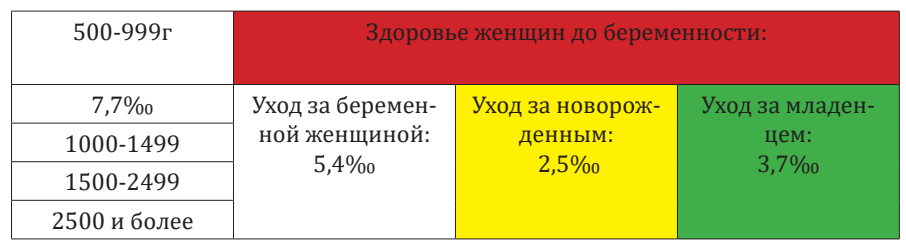

Рисунок 4- Факторы, определяющие плодово-младенческие потери в Казахстане. 2015 г (в \%о)

500-999Г - масса тела при рождении. 1000-1499 - масса тела при рождении. 1500-2499 - масса тела при рождении. 2500 и более - масса тела при рождении.

Одним из наиболее значимых факторов, определяющих плодово-младенческие потери, по-прежнему, является состояние репродуктивного здоровья женщин до беременности - 7,7\%о. Несмотря на снижение этого показателя на 3,8\%о по сравнению с 2008 годом, его доля в общем показателе плодово-младенческих потерь остается высокой, составляя 39,9\% в 2015г. Это свидетельствует о необходимости усиления мер, направленных на улучшение репродуктивных исходов, таких как улучшение питания женщин в плане предупреждения микронутриентной недостаточности, поддержка здорового образа жизни, обеспечение планирования семьи, профилактика и лечение инфекций, передаваемых половым путем. Дальнейшего усиления требует уход за беременными в антенатальном периоде.

Значительно снизился вклад в плодово-младенческие потери такого фактора, как уход за новорожденными в родильном доме: с 7,2\%о в 2008г. до 2,5\%о в 2015г., что положительно коррелирует со снижением показателя ранней неонатальной смертности и свидетельствует об эффективности внедряемых в практику родовспоможения новых технологий ухода и медицинской помощи новорожденным.

В структуре плодово-младенческих потерь снизилась доля такого фактора, как «уход за младенцем после выписки из родильного дома» с 6,2\%о в 2008 г до 3,7\%о в 2015 г. Это свидетельствует об эффективности внедряемых в практику ПМСП и неспециализированных стационаров стратегии ВО3 по интегрированному ведению болезней детского возраста. 
Приведенные факты свидетельствуют об имеющихся резервах, которые могут способствовать дальнейшему улучшению основных показателей, характеризующих качество медицинских услуг в системе детства и родовспоможения для достижения показателей экономически развитых стран (например, США, рис. 5).

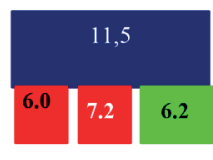

$30.9 \%$

Казахстан, 2008 г.

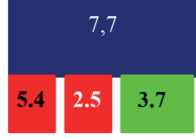

$19.3 \%$ Казахстан, 2015 г.

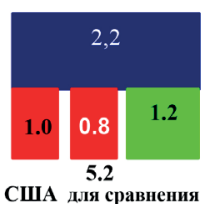

Рисунок 5- Факторы, определяющие плодово-младенческие потери в Казахстане, (\%о)

Синим цветом - здоровье женщин до беременности. Красным цветом -уход за беременной женщиной. Красным цветом с белыми цифрами - уход за новорожденным. Зеленым цветом - уход за младенцем до 1 года.

Согласно заключению Межведомственной Группы Организации Объединенных Наций по оценке уровня смертности [10], Казахстан, начиная с конца 1990$\mathrm{x}$ года, добился значительного прогресса в снижении уровня младенческой и детской смертности на 64 и 65\% соответственно. По их расчетам в Казахстане показатель смертности детей до 5 лет, начиная с 2000 года, снижался примерно на 6,5\% в год. Страна досрочно выполнила Цель 4 по снижению смертности детей от 0 до 5 лет к 2014 году (рис.6).

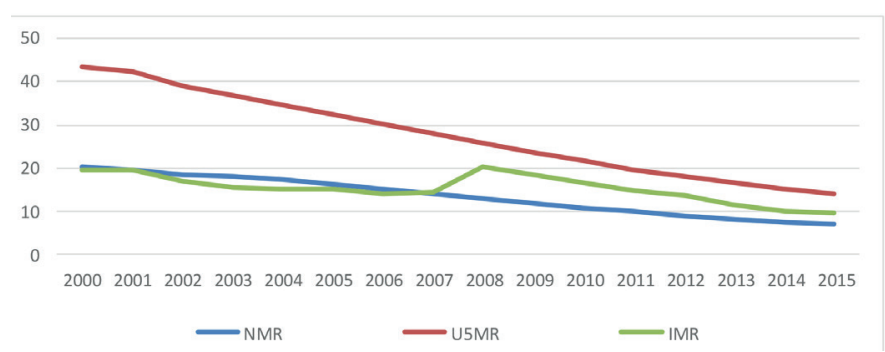

Рисунок 6- Динамика детской, младенческой и неонатальной смертности на 1000 родившихся живыми. Казахстан, 20002015 (Источник: IGME) [10].

NMR - уровень неонатальной смертности. U5MR - уровень детской смертности. IMR - уровень младенческой смертности.

\section{Литература:}

1. Chuvakova T., Kasonde J. Causes of infant and child mortality in Kazakhstan. UNICEF. 2003; 58.

2. Chuvakova T., Gorbunova L. Millennium Development Goals in Kazakhstan. Goal 4. To Reduce Child Mortality. Target 5. To Reduce by two thirds, between 1990 and 2015, the under-five mortality rate. 2005; 42-55.

3. Chuvakova T.K. Snizhenie detskoi smertnosti v Kazakhstane: situacia, problemi, kluchevie intervencii (Reducing child mortality in Kazakhstan: situation, problems, key interventions) [in Russian]. Doklad na zasedanii Parlamenta RK. 2005.

4. Rasporajenie Premier Ministra RK za № 38 ot 01.03.2006 g “Ob utverdjenii Plana meropriyatii po perehodu Respubliki Kazakhstan na kriterii djivorojenia i mertvorojenia, rekomendovannie vsemirnoy organizaciey zdravoohraneniya".

5. Lawn J., McCarthy B.J., Ross S.R. The Helthy Newborn. A Reference Manual for Program Managers. CDC. CCHI, 2000.

6. Pregnancy, Childbirth, Postpartum and Newborn Care. A guide for essential practice. World Health organisation, Geneva 2006.

7. Provision of inpatient care for children. World Health organisation. 2006, 2013.

8. Integrated management of childhood illnesses from 2 months to 5 years. World Health organisation. 2005.

9. Pravitelstvennaya rabochaya gruppa I Mejevedomstvennaya gruppa OON po raschetu pokazateley detskoy smertnosty, g. Astana, Kazakhstan, 22-25 iun 2003g. 